\title{
STUDYING LANGUAGE AS A COMPLEX ADAPTIVE SYSTEM
}

\author{
WiLLIAM CROFT \\ University of New Mexico
}

\begin{abstract}
In the past thirty years, a variety of approaches to linguistic analysis have emerged under the name of "functionalism," including construction grammar, cognitive linguistics, typology and universals research, the usage-based model, and evolutionary approaches to language change. All of these approaches have shed new light of the relationship between grammatical form and meaning in language. In the twenty-first century, these seemingly diverse approaches to language can be integrated into the study of language as a complex adaptive system.*
\end{abstract}

Keywords: construction grammar, conceptual semantics, typology, universals, language change

1. Prospects of Linguistics: A Perspective from Cognitive Linguistics, Typology and Universals, and Usage-Based Linguistics

As we enter the second decade of the twenty-first century, we find a great diversity of theoretical approaches to the study of language. Some of these approaches are grouped broadly under the label of "functionalist linguistics," but in fact they appear to be quite different in their orientation and their subject matter. In my own research, I have published books in several of the approaches to language labeled "functionalist," in particular construction grammar (Radical Construction Grammar (2001)), conceptual semantics (Verbs: Aspect and Causal Structure (2012)), typology and universals (Typology and Universals (2nd edition, 2003)) and language change (Explaining Language Change: An Evolutionary Approach (2000)).

How are all of these different perspectives linked together? A con-

* I wish to thank the organizers of the 30th Anniversary Convention of the English Linguistic Society of Japan for inviting me to present this paper, and the audience of the presentation for their comments and questions. All errors remain my own.

English Linguistics 31: 1 (2014) 1-21 - 1-

(C) 2014 by the English Linguistic Society of Japan 
structional approach to grammatical structure provides a way to represent linguistic form and its relation to meaning. The study of conceptual semantics contributes the motivating factors for grammatical structure. Typology yields the universals that hold for human beings across cultures. And language change presents an overarching view of language as a complex adaptive system evolving within and across the lifetimes of speakers. In this article, I briefly describe each of these perspectives, and how they fit together to a single coherent approach to language as a complex adaptive system.

\section{Construction Grammar}

Construction grammar provides a novel organization of grammatical knowledge in contrast to the widely used componential model. In the componential model, different types of grammatical information-phonological, syntactic, semantic, pragmatic - are each treated as belonging to distinct components in the mental representation of grammatical knowledge (Croft and Cruse (2004: 225-227)). It is assumed that there is a body of grammatical rules that pertain exclusively to each type of grammatical information. Nevertheless, different components need to be linked together in the componential model, since what is produced and comprehended are utterances consisting of phonological and syntactic units, which convey an intended semantic and pragmatic interpretation to the addressee. The basic means by which phonological, syntactic and semantic information are linked together is via the lexicon: words have phonological form, syntactic properties, and meaning. The lexicon alone is not enough, because sentences have meanings depending on how words are put together, and syntactic structures must be realized in phonological form. For this reason, linguists working in the componential model have proposed interpretation rules, interface rules, linking rules, and/or realization rules that link together complex structures from different components, such as the argument realization rules linking semantic structures to syntactic structures (Levin and Rappaport Hovav (2005)).

Construction grammar focuses on the need to link together grammatical information from different components that is found in the componential model, and develops it into an alternative way to represent grammatical knowledge. There are many syntactic patterns that are not as general as the most schematic clausal pattern (subject-predicate, or the traditional generative phrase structure $[\mathrm{NP} V P]_{\mathrm{S}}$ and its more recent formulations), but 
are not strictly fixed lexical idioms such as kick the bucket or for better or for worse. In a classic article now twenty-five years old, Fillmore, Kay and O'Connor (1988) explore a range of these partially schematic, partially substantive structures, which they call constructions, using the traditional name. The construction that Fillmore et al. explore in greatest detail is the let alone construction, illustrated in (1) (emphasis indicates accent):

(1) Max won't eat SHRIMP, let alone SQUID.

(2) Max won't TOUCH the SHRIMP, let alone CLEAN the SQUID.

The let alone construction is somewhat complex to describe in syntactic terms: it consists of two (sometimes more) clauses, the first full and the other(s) reduced; there is a conjunction let alone that links the clauses; the construction has negative polarity for most speakers; and there is at least one paired focus, manifested prosodically by accent. The main point of Fillmore et al.'s argument is that the let alone construction is a productive syntactic structure - a construction - that can generate an indefinite number of sentences, just like a more schematic syntactic structure; yet it has lexically specific parts (the conjunction let alone), and its grammatical properties cannot be wholly predicted from other syntactic structures. That is, the let alone construction cannot be represented as a predictable combination of grammatical properties following from, for instance, coordinated sentences, focus constructions with multiple paired foci, or negative polarity items.

In addition, the let alone construction is a specialized syntactic structure with an equally specialized, but general, semantic interpretation. The let alone construction has a systematic semantic interpretation ranking paired propositions on aligned scalar models. The propositions - in (1), Max not eat shrimp and Max not eat squid-must be in the same scalar model, in this case a model of eating seafood of various kinds. A scalar model implies a ranking of eating seafood of different kinds, such that for example eating squid is less likely than eating shrimp. The propositions must have the same polarity (both negative). The initial, full conjunct denotes the proposition that is stronger or more informative on the scale: in this case, Max not eating shrimp is more informative than Max not eating squid. In addition, the construction is generalizable to multiple paired foci, as found in (2) (touch vs. clean as well as shrimp vs. squid).

Fillmore et al. are not the only linguists to have argued that particular constructions have their own distinct syntax and semantics (and also in some cases, phonology and pragmatics). Many other linguists working in different theoretical traditions have proposed constructional analyses over the past thirty years. Ellen Prince and her colleagues have described a 
wide range of information structure constructions with unique pragmatic as well as syntactic properties (e.g. Prince (1978), Birner and Ward (1998)), as have also Knud Lambrecht and Laura Michaelis (Lambrecht (1984, 1988, 1990) and Michaelis and Lambrecht (1996)). Anna Wierzbicka pioneered a number of highly insightful syntactic and semantic analyses of a variety of constructions in English, ranging from highly schematic constructions such as various types of coordination (Wierzbicka (1980)), through to have a $\mathrm{V}$ constructions (have a drink; Wierzbicka (1982)) and specific types of tautologous sentences (Boys will be boys; Wierzbicka (1987)), all with several subtypes whose properties are not predictable from the more general structure. Adele Goldberg and Ray Jackendoff have proposed a constructional analysis of resultatives (Goldberg and Jackendoff (2004)), and Jackendoff has also published an analysis of the 'time'-away construction (Jackendoff (1997)). Finally, George Lakoff presents a detailed analysis of a wide variety of There-constructions in English (Lakoff (1987)).

From this range of analyses of specific constructions in English, one can draw the conclusion that there is a very large number of semi-schematic but productive constructions in English with their own distinct syntax and semantics (see also Culicover (1999)). In fact, careful analysis usually reveals that each of these constructions has a number of subtypes each of which also has its own set of unique syntactic and/or semantic properties not predictable from more general syntactic structures or rules of semantic interpretation. This observation led Fillmore et al. to propose a model of grammatical representation, construction grammar, that in some ways turns the componential model on its head. Instead of components with highly general self-contained rules of combination and rules linking together components, in construction grammar there are constructions, each of which is a set of "rules" linking syntax and semantics (and phonology and pragmatics). Constructions may be semi-schematic, such as the let alone construction or the 'time'-away construction. But a 'construction,' in the sense of a structure linking form and meaning, can range from the most schematic construction, such as the transitive construction, and its semantic interpretation, to the most substantive unit, namely a lexical item with its form (phonological and syntactic) and meaning. In other words, construction grammar provides a uniform and highly general means to represent grammatical structures. All grammatical structures, from a single word to the most schematic syntactic structure and semantic interpretation rule, are constructions in the modern conception of construction grammar. 


\section{Conceptual Semantics}

The role of meaning in grammar is often misunderstood. Grammatical form and meaning do not match. For this reason, some linguists treat syntax and semantics as completely independent of each other, as implied in the componential model described in section 2. But that is not the best analysis either. Even the componential model has linking or realization rules between syntax and semantics - and they often imply some highly general iconic principles. In section 2, I argued that highly general principles of mapping from form to meaning will not succeed, because form and meaning are mismatched too often and in sometimes idiosyncratic ways.

Yet the truth is, meaning motivates form. That is, syntactic structure is strongly influenced by meaning. The complexity in the form-meaning mapping is due to the fact that there are competing semantic motivations as to how meaning is encoded in grammatical form. These competing motivations arise in part due to the nature of semantics. Meaning is conceptualization or construal, an approach to meaning advocated by linguists as theoretically disparate as Langacker (1987) and Jackendoff (1983). An experience that is to be verbalized has to be conceptualized in a certain way. Experiences can be conceptualized in different ways, and one consequence is that the grammatical structure(s) used to express that meaning can vary within a language, leading to a degree of indeterminacy in the mapping between meaning and form. Sometimes particular variations in encoding meaning become established as convention in different speech communities, and the result is crosslinguistic variation.

For example, the encoding of event participants as arguments of a predicate is seemingly very complex, and meaning does not predict the argument structure of a clause. The semantic roles underlying specific grammatical roles such as Subject, Object and Oblique are extremely diverse: agent, patient, instrument, theme, recipient, experiencer, etc. But there is a quite simple way to characterize Subject and Object choice, in terms of the construal of a force-dynamic relationship between participants in events, that is, their position in a causal chain (Croft (1991, 1998, 2012)).

Consider a simple sentence with a single predicate and four arguments, denoting an event with four participants (Croft (2012: 198)):

(3) Sue broke the coconut for Greg with a hammer.

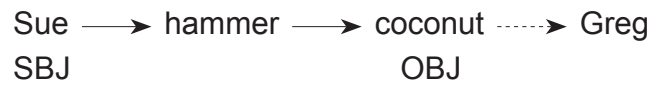

The force-dynamic structure of the event is a causal chain: Sue acts on the 
hammer (grasping it and applying force to it), the hammer in turn transmits force to the coconut; the coconut breaks and the outcome of this event benefits Greg. The causal chain is directed (asymmetric), cyclic and nonbranching. This is what is most important about the roles of these four participants in the event from a grammatical point of view, not that the roles correspond to agent, instrument, patient and beneficiary. As we will see shortly, the representation of the event as a causal chain is a construal of the event, but in this case, this construal is quite natural.

From the force-dynamic analysis of the event in (3), a part of the causal chain, specifically the part from Sue to the coconut, is selected by a speaker as the segment to be profiled by the verbal predicate (Croft (2012: 206)). This is another construal of the event: different choices of verb, or of verbal form (e.g. a nonactive voice form), imply a different verbal profile selected by the speaker. Languages allow for these alternatives because speakers will want to profile different parts of the event for different purposes in the discourse. This is the first principle of construal: an experience may be construed in different ways in a language for the purposes of the discourse.

The causal chain and verbal profile determine the choice of Subject, Object and Oblique grammatical roles for the participants in the event. The Subject and the Object delimit the verbal profile, in this case, Sue and the coconut. The Subject is Antecedent to the Object in the causal chain: Sue, the Subject, acts on the coconut, the Object. This transmission of force relationship between Subject and Object accounts for the relatively high degree of uniformity of the encoding of participants of very different kinds of events in very different kinds of participant roles across a wide range of languages.

Finally, the encoding of participants in Oblique roles follows a twofold rule. There are usually a variety of Oblique grammatical roles, but they generally divide themselves into two types: those used to encode participants that are antecedent to the Object in the causal chain, and those used to encode participants that are subsequent to the Object in the causal chain. We will call these Antecedent and Subsequent Obliques (Croft (1991: 184-192, 2012: 206-208)).

This abstract characterization of events and their semantic structure represents how speakers conceptualize event structure in clauses. But not all events are as straightforward to conceptualize in this way. For example, in verbs of application such as load, the relationship between the thing loaded and the place where it is loaded is a spatial relation of figure and ground, 
not a causal relationship of transmission of force. Yet when one examines the grammatical encoding of figure and ground in application events in English and other languages, there appears to be a general pattern of conceptualization of the figure-ground relation: the figure is construed as antecedent to the ground in the causal chain. But even so, the choice of Object, and hence the verbal profile, allows for two variants in English.

(4) Jack loaded the furniture on the truck.

(5) Jack loaded the truck with the furniture.

In (4), the figure in the spatial relation is selected as Object. As a consequence, the ground is subsequent to the Object in the causal chain (thanks to the construal of the figure as first), and is expressed by a Subsequent Oblique form (a normal spatial adposition). In (5), the ground in the spatial relation is selected as Object. As a consequence, the figure is antecedent to the Object in the causal chain, and is expressed by an Antecedent Oblique form, the Instrumental preposition with (Croft (1991: 198-206, 2012: 226-233)). The alternation appears to conform to a subtle semantic difference, possibly best described in terms of how incremental progression through the event is measured (by changes in the participant coded as Object; Dowty (1991); Croft (2012: 307-318)).

The English grammatical constructions in (4) and (5) show how alternative construals of the same application event conform to general patterns of event construal. Participants are construed to be ordered in a causal chain. Noncausal relations are construed as asymmetric so that they are integrated into the causal chain; the figure-first construal illustrated in (4) and (5) is crosslinguistically quite general. When the ground rather than the figure is encoded as Object, the figure is expressed in an Antecedent Oblique form.

But there is also variation in the options found, and this variation leads to differences across languages and even within languages. In English, the verb form in (4) and (5) is identical; in most other languages, the verb form in the corresponding argument structure to (5) is morphologically derived. Most languages have more than one Antecedent Oblique form, and the form chosen may not have the same range of functions as English with. Some languages allow only one of the argument structures found in (4) and (5) (usually but not always the one in (4)). (For detailed documentation of these patterns, see Croft $(1991,2012)$, and references cited therein.)

There is a great deal of variation in these fine-grained details, within and especially across languages; and one must capture all of this detail 
in a genuinely complete description of a speaker's knowledge about their language. An important methodological advance in the last two decades is the use of corpus data, both transcribed conversation and large-scale electronic databases, to discover the range of fine-grained variation in these patterns. The exploration of corpora has revealed a fine-grained richness of both syntactic and semantic detail in language use.

For example, an electronic corpus revealed semantic types of reciprocal expressions that had not been previously recognized in the theoretical literature on reciprocals (Dalrymple et al. (1998)). Two such examples from Dalrymple et al.'s paper are illustrated with their corpus examples in (6) and (7):

(6) "The captain!" said the pirates, staring at each other in surprise.

(7) They climbed a drainpipe to enter the school through a high window and stacked tables on top of each other to get out again. The semantic type in (6) is called one-way weak reciprocity by Dalrymple et al.: each individual is acting on another individual in the set, and may be acted upon by another individual in the set; but it is not necessarily the case that each individual is both acting and acted upon, and not in a pairwise reciprocal relationship. The semantic type in (7) is called intermediate alternative reciprocity by Dalrymple et al.: the individuals are in a chaining relationship (as in The soldiers followed each other across the field), but the chain may branch (imagine one table stacked on two others which in turn are stacked on three others).

Dalrymple et al.'s research demonstrates that examining actual language use reveals semantic types of syntactic constructions that might not otherwise be recognized. A large-scale project of semantic analysis based on large electronic corpora is the FrameNet project directed by Charles Fillmore at the University of California, Berkeley (https://framenet.icsi. berkeley.edu/fndrupal/). FrameNet documents the participant roles found in corpora for an enormous number of event types, organized into semantic frames, in English (FrameNet has spawned parallel projects for several other languages, including Japanese (http://jfn.st.hc.keio.ac.jp/)). The first thing that strikes a syntactician upon examining a FrameNet semantic frame, such as the Filling frame (including verbs like cover, douse, fill, spray and so on), is the large number of participant roles (called frame elements in FrameNet) for each verb or other predicate in the frame. For example, the Filling frame includes Agent, Cause, Goal, Theme, Degree, Depictive, Instrument, Manner, Means, Path, Place, Purpose, Reason, Result, Source, Subregion and Time. The advent of large corpora has revolutionized the 
study of syntax, particularly its relationship to semantics and also the acquisition of syntax by children (see Tomasello (2003)).

\section{Typology and Universals}

The amount of fine-grained variation found in actual language use in individual languages is reflected in fine-grained variation across languages. Indeed, the variation across languages is greater than the variation within languages. Typological research has revealed a huge degree of diversity across languages. One consequence of this diversity is that an analyst of a single language, such as English, must situate the particular combination of structural and semantic features found in the language in the larger context of crosslinguistic variation that ultimately reveals the universals underlying the expression of meaning in linguistic form.

Typological research has revealed that the structure of constructions is much more varied than originally believed, based on the structural analysis of those constructions in English and a small number of other languages. For example, the English passive in (8) is usually defined structurally in terms of "promotion" of the patient to the Subject role, "demotion" of the agent to an Oblique role, and morphological derivation of the verbal predicate:

(8) She was introduced by the chairman.

But surveys of "passive" constructions across languages reveals a much greater structural diversity than the English type suggests. In a language as near to English geographically and genetically as Welsh, one finds a passive in which a pronominal patient remains in the Object form (Comrie (1977: $55)$ ):

(9) fe'i lladwyd gan ddraig

Ptcl'Obj killed.Pass by dragon

'He was killed by a dragon.'

In Bambara, a Mande language in west Africa, the verb remains underived, even though the patient is expressed as Subject and the agent as an Oblique (Croft (2001: 293), from Chris Culy (pers. comm.)):
(10)
fo 'ra
dugutigi fè
$3 \mathrm{sg}$ greet 'Comp.Intr chief with
'S/he was greeted by the chief.'

In Arizona Tewa, a Tanoan language in the American Southwest, the verb agrees with both agent and patient in a special paradigm found only with the "passive voice" (Kroskrity (1985: 313)): 
(11) u khóto hę’i sen -di wó:- mégi you bracelet that man -Obl 2/3.Pass- give 'You were given a bracelet by that man.'

Instead of treating syntactic constructions as grammatical types that are found across languages, a better analysis is to treat syntactic constructions as language-specific, but possessing grammatical properties that define a "syntactic space" of possible construction types (Croft (2001: 310-314)). For example, the syntactic space for voice constructions includes variation on the following "dimensions": how the agent argument is encoded by case marking, verb indexation (agreement) and word order; how the patient argument is encoded by case marking, indexation and word order; and the form of the verb. All these parameters can vary partly independently; there are no discrete structural types corresponding to a putative "active" or "passive" (or "inverse," another voice type that is discussed in the typological literature); this argument has been made by a number of typologists (Siewierska (1985: 1); Thompson (1994: 61); Shibatani (1985: 821); Croft (2001: 310)). That syntactic space can then be associated with the conceptual space representation the function of "active," "passive," and "passive-like" voice constructions across languages. Making this comparison reveals that nonbasic ("passive" or "inverse") voice constructions vary with the degree of structural deviation from the basic ("active" or "direct") voice, and that structural deviation correlates with deviation from the discourse status of the agent as the most topical referent in the clause (Thompson (1994: 48); Cooreman (1987: 76); Croft (2001: 314-317)).

Much research has been done in typology on the relationship between formal grammatical categories and the meanings or functions that they represent. All of this research points to the same conclusion: that all linguistic categories, from the most grammatical-noun, verb, adjective; subject, object (Croft (2001)) - to less grammatical-adpositions (Levinson et al. (2003), indefinite pronouns (Haspelmath (1997)), tense-aspect categories (Dahl (1985)) - to lexical — verbs of cutting and breaking (Majid, Boster and Bowerman (2008)) - are extremely variable from one language to the next. Thus, a model of linguistic knowledge positing a set of universal linguistic categories is inadequate for representing this variation. Instead, typologists have proposed a model in which linguistic categories are constrained by the structure of a conceptual space: although linguistic categories are language-specific, they must denote a connected region in the conceptual space.

Two models have been used to represent the conceptual space: a graph 
structure, usually called the semantic map model (Haspelmath (2003); Croft (2003)), and a continuous Euclidean model, inferred from a multidimensional scaling (MDS) analysis of the crosslinguistic data (Croft and Poole (2008)). An example of the latter is the analysis of spatial adpositions by Levinson et al. (2003). Levinson et al. used the 71 picture stimuli developed by Melissa Bowerman and Eric Pederson for eliciting the linguistic forms used for spatial relations commonly expressed by in or on in English (Pederson and Bowerman (in prep.); the stimuli are published in Levinson and Wilkins (2006: 570-575)). Levinson et al. collected verbalizations of the spatial relations in the stimuli in nine languages, and analyzed the spatial adpositions used by the speakers. The languages varied radically in the categories of spatial relations defined by the adpositions in each language. However, an MDS analysis of the variation in the categories (Levinson et al. (2003); Croft (2010a)) reveals that they conform quite well to a two-dimensional conceptual space.

The MDS analysis of the crosslinguistic spatial adposition data also reveals something more profound about the nature of linguistic categories and the meanings or functions that they express. The 71 stimuli each represent a spatial relation that is slightly distinct from every other spatial relation in the set of stimuli. The location of each of the stimuli in the conceptual space is slightly different as well. This fact, derived from the patterns of linguistic categorization, implies that speakers are sensitive to subtle distinctions among spatial relations in defining the adposition categories in their language. A closer examination of the "IN"-like spatial relations (Croft (2010a)) demonstrates that the relevant dimension of the conceptual space represents degree of envelopment of the figure (the object being located) by the ground (the location): the higher the degree of envelopment, the more extreme an "IN" type the spatial relation is. In other words, linguistic categories do not map into a set of discrete universal conceptual categories, just as linguistic categories themselves do not form a set of discrete universal grammatical categories. Instead, speakers are sensitive to fine-grained variation in the situations they express in language, and certain conceptual dimensions provide the basis for using - and learning - the linguistic categories of their language. Again, these results support the approach to language in which fine-grained variation in both form and meaning is a fundamental aspect of human grammatical knowledge, and language use is sensitive to that fine-grained variation. 


\section{Language Change}

Nowhere is the fine-grained approach to variation more relevant than in the integration of grammatical knowledge with processes of language change. If we start from a view that synchronic knowledge of language is a static, homogeneous entity, then the fact of language change is a puzzle. Why would language change if it is a "perfect" system, and is adequate for the functions it is called on to perform? But if we take the view that language is really a dynamic, constantly adapting system that evolves through language use, then it is natural that language changes. And the view of language as a dynamic complex adaptive system is quite compatible with the linguistic patterns described in earlier sections of this article. In fact, those patterns emerge as the result of a language system continually evolving through language use. A finer-grained examination of synchronic variation reveals how the linguistic system evolves.

Most linguistic analysis - formalist and functionalist-starts from linguistic form and proceeds to meaning. This perspective tends to make the relationship between form and meaning look more stable and settled than it really is. In typology and in various experimental approaches, the analysis starts from meaning and proceeds to form. We call this the verbalization perspective, following Chafe $(1977 \mathrm{a}, \mathrm{b})$. In typology, the immense structural diversity found in the world's languages means that the function of constructions and grammatical forms must act as the basis of comparison. This allows the typologist to get a handle on structural diversity, but the diversity of course remains to be accounted for. In experimental approaches such as the crosslinguistic analysis of spatial relations by Levinson et al. described in the preceding section, speakers are asked to describe the experimental stimuli. The results demonstrate a high degree of variation in verbalization, even among speakers of the same language. Intuitively, this is simply an example of the fact that no two people describe the same scene in the same way - a truism that actually has important theoretical consequences for our understanding of the nature of language.

Chafe has been a pioneer in linguistic theorizing from a verbalization perspective. The aforementioned publications led to the Pear Film project, in which a professional filmmaker produced a short film without language that was designed in part to study patterns of verbalization suggested by the pilot studies reported in Chafe's 1977 publications. Many other researchers have used the Pear Film (and also the Frog Story; see Strömqvist and Verhoeven (2004)) to explore aspects of verbalization and the construction 
of narrative.

Croft (2010b) looks at the Pear stories published in Chafe (1980) in terms of the production and evolution of grammatical constructions. The Pear stories in Chafe (1980) were told by twenty different undergraduates at UC Berkeley. Naturally, the verbalizations of the same scene by different speakers varied tremendously, as illustrated by the way that the speakers verbalized the following scene (speakers 3, 5, 13, 14 and 16 did not verbalize this scene):

1 [3.3 [.85] A-nd u-h [1.5]] and then he gets down out of the tree,

2 [1.6? and [.5]] anyway, he comes down with a load of pears,

$4 \quad[1.4[.55\{$ laugh $\}]$. . . a--nd [.35]] he walked down the ladder,

$6[.5]$ and he walks down the [.75] ladder,

7 [2.25 [.6] tsk [.1] A--nd [.75]] he-- [.35] was going up and down the ladder,

8 and comes down,

9 he comes off of the ladder,

10 and then he'll walk down the ladder,

11 [.4] climbs down the ladder,

$12[.85] /$ the whole idea/ he picked pears came down the ladder,

15 [2.65 [1.4] A--nd [.8]] he went down the ladder,

17 [1.05? [.35] and the--n . . u--m . . ] going . . down off the ladder,

18 [1.4 [.9] tsk And then . . ] climbing very carefully . . down the [.2] the ladder,

19 And he comes down, . . from the ladder,

20 [.6] So he didn't have to go down to the ground,

If one focuses on particular parts of the utterance, such as the verb chosen, patterns in language behavior emerge more clearly from the variation. For example, one can compare the five scenes in the Pear film where at least one speaker produced the verb put to describe the scene:

\begin{tabular}{|l|l|l|l|l|}
\hline put & Other verb & Other verbs used & Object being 'put' & Instrument \\
\hline 15 & - & & singular & hand \\
\hline 8 & 2 & drop, stuff & distributive & hand \\
\hline 8 & 4 & load, throw, toss, pour & plural & hand \\
\hline 9 & 13 & $\begin{array}{l}\text { empty, dump, tumble, drop, } \\
\text { place, deposit }\end{array}$ & plural & apron \\
\hline 1 & 6 & deposit, dump, empty, unload & plural & apron \\
\hline
\end{tabular}


In all but one of the scenes, some speakers used verbs other than put. However, the proportion of put, and the alternative verbs chosen, vary from scene to scene in semantically systematic ways. If the object being "put" is singular, and a hand is the instrument for putting the object in its location, then put is universally used by this sample of speakers. As one moves away from this prototypical putting event, with distributed or plural objects and something other than a hand functioning as the instrument of putting, then other verbs are increasingly likely to be used.

We can infer from this that the form-meaning mapping is a many-to-many relation. Not only are forms used for multiple meanings-a well-known result from research in the form-to-meaning perspective-but meanings are expressed in multiple different forms. And not only this, but the formmeaning mapping - the symbolic relation that is the heart of language - is a probabilistic one, in terms of the likelihoods of particular words being used to verbalize particular situations, as measured by experimental data such as the Pear Film stories. And the probabilities are sensitive to fine-grained differences in the situations being expressed, in a semantically systematic way, as seen in the putting example. Just as linguists can infer the probabilities of particular form-meaning mappings, so do users and learners of the language. Their observations of language use hone their understanding of the expressiveness of different words and constructions to convey particular situations in quite fine detail. This is the essence of language as a complex adaptive system: sensitivity to a complex set of intersecting dimensions of meaning, and a constant interaction between speaker, hearer and the situations being communicated that evolves over successive interactions.

Grammar involves a probability distribution of forms across meanings in conceptual space. Grammatical change, therefore, is a shift in the probability distribution of forms across meanings in conceptual space over time. Grammatical change originates in the variation of verbalization of experience in language use. Evidence supporting this interpretation can be found by comparing the alternatives to what we think of as the most grammaticalized form used in verbalization to the etymological origins of those forms across languages. In Croft (2010b), I compare the alternatives to the most general verbs (such as put) found in the Pear stories to the etymological source of the general verbs in a comparative dictionary of Indo-European (Buck (1949)). There is almost complete overlap between the alternative verbs used for put in the Pear stories and the verbs that serve as the etymological source of 'put' verbs in Indo-European: 


\begin{tabular}{|l|l|l|}
\hline $\begin{array}{l}\text { Alternative } \\
\text { verb in Pear } \\
\text { stories }\end{array}$ & Indo-European 'put' verb & Source/related verb in older language \\
\hline throw, toss & Modern Greek vazo & $\begin{array}{l}\text { Ancient Greek bállo 'throw, occasionally } \\
\text { 'put' }\end{array}$ \\
\cline { 2 - 3 } & $\begin{array}{l}\text { French mettre, Italian } \\
\text { mettere, etc. }\end{array}$ & $\begin{array}{l}\text { Latin mittere 'let go, throw, Late Latin } \\
\text { 'put' }\end{array}$ \\
\cline { 2 - 3 } & Modern Irish cuirim & Old Irish cuirim 'throw, put' \\
\hline \multirow{2}{*}{ stuff } & English put & Old English potian 'thrust, push' \\
\hline place & Dutch plaatsen & Dutch plaats 'place [n.]' \\
\hline
\end{tabular}

Language change, like other evolutionary processes, is a two-step process: the generation of variation-known in linguistics as innovation - and selection-known in linguistics as propagation (Croft (2000)). If we recognize that language change involves these two steps, we can see that the two seemingly incompatible research programs of historical linguistics - the traditional, mostly philological, study of innovations (sound changes, lexical changes and constructional change/grammaticalization) and the sociolinguistic study of language change in progress - are actually complementary studies of the two distinct steps in language change. And if we recognize that the study of innovations ultimately brings us to the process of verbalization, that is, language use, then we can see that there is no difference between studying language "synchronically"-how speakers gain and employ their knowledge about their language - and studying language "diachronically"-also how speakers gain and employ their knowledge about their language. In fact, propagation of language changes as well as their innovation happens in speaker's lifetimes: both processes emerge from language use.

Language use is the nexus of language as a complex adaptive system. Language use is where linguistic structures are replicated and speakers' knowledge of language is affected as a consequence. Adaptation is an interaction between all of the environmental factors that influence the production and comprehension of an utterance: the nature of the experience to be communicated; the speaker's knowledge about her language; the shared knowledge and beliefs of the speaker and hearer (i.e. their common ground); the social relationship between the speaker and hearer, including their personal relationship, their role and standing in their society, and the social context of the utterance. All of these factors are part of the complex adaptive system of language. Each utterance is influenced by these factors, and the result of that utterance may bring about changes not just in speaker 
and hearer's shared knowledge but also in their social relationship and even the natural environment in which their lives take place. A full understanding of language as a complex adaptive system therefore involves all the scholarly subdisiciplines of linguistics and their integration into the study of language.

\section{Conclusions: The Future of Linguistics}

Language is a complex adaptive system (Beckner et al. (2009)). As the careful analyses of syntax by construction grammarians have shown, all grammatical units from single words to various types of "idioms" to the most schematic syntactic structures are pairings of form and meaning (semantic interpretation). There are many subtle distinctions among grammatical constructions and subtypes of constructions that are best observed in large corpora of actual language use (written or spoken, now more easily accessible in electronic form).

Meanings represent a conceptualization of experience-that is, how speakers package that experience for the goals that they wish to attain in discourse. Grammatical constructions perform conceptual information-packaging functions such as reference, predication, modification, argument status, and many other functions. Analysis of meanings in corpora of actual language use shows that many subtle variations in the situation types expressed by particular constructions occur that are not always imagined in introspective analysis.

Typological research reveals the extraordinary diversity of grammatical constructions and their functions across languages. From this observation, one can conclude that the form of grammatical constructions is not best represented as combinations of primitive syntactic categories. Instead, constructions vary among many different dimensions of grammatical form, defining a syntactic space of grammatical variation that is nevertheless constrained by the types of functions the constructions perform. Likewise, typology reveals that the meaning of constructions is not best represented as combinations of primitive conceptual categories. Instead, meaning is best represented as fine-grained relationships among subtly different situation types, often along continuous dimensions of conceptual variation.

All of these analyses are based on fine-grained studies of language use, within and across languages. It turns out that speakers are very sensitive to fine-grained differences of form and meaning that are found in actual language use. If we take a verbalization perspective on language form, the 
degree of variation found in language expands dramatically. But the variation is all structured. It is just that there is no simple one-to-one mapping between form and meaning, any more than there is a simple set of syntactic or semantic building blocks for constructions and their meanings. Instead, linguistic knowledge is a probability distribution of grammatical forms across meanings acquired through language use and continually evolving through a speaker's lifetime. The probability distribution is the source of the variation that we observe in language; that variation may be propagated in speech communities (a social process), and propagated in different directions in different speech communities, leading to the typological diversity of languages in every aspect of grammar.

This is the picture of language that emerges from research in the past thirty years in construction grammar and corpus linguistics, conceptual semantics, typology and universals, and experimental and sociolinguistic (observational) research on language change. Parallel conclusions have been drawn for sound structure, in exemplar and usage-based phonology (see Bybee (2001) and Pierrehumbert (2003a, b), among others.) The research in these several areas have progressed to the point that we can present a unified and coherent theory of language as a complex adaptive system, as outlined in this article and described in greater detail in the references cited herein.

Of course, as in all scientific research, there is always more to explore about the nature of language as a complex adaptive system. For the future of linguistics, advances in several areas are urgently needed.

First, greater focus on the verbalization perspective in the analysis of linguistic form is needed. A verbalization perspective allows us to observe the fundamental dynamics of language as a complex adaptive system. (It also incidentally helps to answer the practical question of how to express oneself in another language in second language acquisition-not a simple question to answer.)

Second, we must increase the granularity of the data that is collected for linguistic analysis. The use of not just two or three but 71 pictures of 'in'-'on' relations, and the examination of some fifty scenes from the Pear film across twenty speakers, shows that speakers consistently make very fine-grained judgements about the form-meaning mapping. Research on language acquisition sampling the acquisition process at much shorter intervals shows that syntactic acquisition is a very gradual process (Lieven et al. (2003)). Last but not least, detailed documentation of a large number of languages across many language families and cultural-geographical regions 
has uncovered degrees of variation that can hardly be imagined in the study of just English and selected western European and east Asian languages. This aspect of fine-grained linguistic analysis is essential: how can one be confident of proposed universals of grammar without knowing what the phenomenon in question looks like across a proper sample of the world's languages? Unfortunately the vast majority of human languages are highly endangered due in part to social and economic processes beyond the control of linguists, and so this is by far the most urgent task for 21 st century linguistics.

Third, linguists must deploy and/or develop quantitative methods in analysis of the vast amounts of fine-grained data that is necessary to the study of language. Some of these quantitative methods have been developed for the analysis of phenomena with parallel structure and behavior to language (use) in other fields, such as evolutionary biology, statistical mechanics, and political science. Specialists in those fields have started to apply such methods to linguistic questions, for better or for worse. Quantitative methods must always be combined with qualitative analysis and interpretation of the type that linguists have traditionally been trained to do. Nevertheless, linguistics would benefit tremendously from the employment of more sophisticated quantitative methods (and, of course, the training of future linguists in the use of those methods).

Finally, there must be a fuller integration of typology, grammatical analysis, semantics and pragmatics, sociolinguistics and language change into a model of language as a complex adaptive system. Linguistics has fissioned into a large number of specializations. I believe that this fission, while allowing advances in our understanding of particular aspects of language, risks our losing sight of the big picture of what is the nature of language and language behavior in human beings. Future linguists must not only be trained to some degree in each of the areas of linguistics named above, but also be challenged to find the interconnections between all of these areas and how they all function as part of the explanation of language as a complex adaptive system.

\section{REFERENCES}

Beckner, Clay, Richard A. Blythe, Joan L. Bybee, Morten H. Christiansen, William Croft, Nick C. Ellis, John Holland, Jinyun Ke, Diane Larsen-Freeman and Tom Schoenemann (2009) "Language is a Complex Adaptive System," Language 
Learning 59: Supplement 1, 1-26.

Birner, Betty J. and Gregory Ward (1998) Information Status and Noncanonical Word Order in English, John Benjamins, Amsterdam.

Buck, Carl Darling (1949) A Dictionary of Selected Synonyms in the Principal IndoEuropean Languages, University of Chicago Press, Chicago.

Bybee, Joan L. (2001) Phonology and Language Use, Cambridge University Press, Cambridge.

Chafe, Wallace (1977a) "Creativity in Verbalization and Its Implications for the Nature of Stored Knowledge," Discourse Production and Comprehension, ed. by Roy Freedle, 41-55, Ablex, Norwood, NJ.

Chafe, Wallace (1977b) "The Recall and Verbalization of Past Experience," Current Issues in Linguistic Theory, ed. by Peter Cole, 215-246, Indiana University Press, Bloomington.

Chafe, Wallace, ed. (1980) The Pear Stories, Ablex, New York.

Comrie, Bernard (1977) "In Defense of Spontaneous Demotion: The Impersonal Passive," Grammatical Relations, Syntax and Semantics 8, ed. by Peter Cole and Jerrold M. Sadock, 47-58, Academic Press, New York.

Cooreman, Ann (1987) Transitivity and Discourse Continuity in Chamorro Narratives, Mouton de Gruyter, Berlin.

Croft, William (1991) Syntactic Categories and Grammatical Relations: The Cognitive Organization of Information, University of Chicago Press, Chicago.

Croft, William (1998) "Event Structure in Argument Linking," The Projection of Arguments: Lexical and Compositional Factors, ed. by Miriam Butt and Wilhelm Geuder, 1-43, CSLI Publications, Stanford.

Croft, William (2000) Explaining Language Change: An Evolutionary Approach, Longman, Harlow, Essex.

Croft, William (2001) Radical Construction Grammar: Syntactic Theory in Typological Perspective, Oxford University Press, Oxford.

Croft, William (2003) Typology and Universals, 2nd ed., Cambridge University Press, Cambridge.

Croft, William (2010a) "Relativity, Linguistic Variation and Language Universals," CogniTextes 4.303. <http://cognitextes.revues.org/303/>

Croft, William (2010b). "The Origins of Grammaticalization in the Verbalization of Experience," Linguistics 48, 1-48.

Croft, William (2012) Verbs: Aspect and Causal Structure, Oxford University Press, Oxford.

Croft, William and D. Alan Cruse (2004) Cognitive Linguistics, Cambridge University Press, Cambridge.

Croft, William and Keith T. Poole (2008) "Inferring Universals from Grammatical Variation: Multidimensional Scaling for Typological Analysis," Theoretical Linguistics 34, 1-37.

Culicover, Peter (1999) Syntactic Nuts: Hard Cases, Syntactic Theory, and Language Acquisition, Oxford University Press, Oxford.

Dahl, Östen (1985) Tense and Aspect Systems, Basil Blackwell, Oxford. 
Dalrymple, Mary, Makoto Kanazawa, Yookyung Kim, Sam Mchombo and Stanley Peters (1998) "Reciprocal Expressions and the Concept of Reciprocity," Linguistics and Philosophy 21, 159-210.

Dowty, David (1991) “Thematic Proto-Roles and Argument Selection," Language 67, 547-619.

Fillmore, Charles J., Paul Kay and Mary Catherine O'Connor (1988) "Regularity and Idiomaticity in Grammatical Constructions: The Case of let alone," Language 64, 501-538.

Goldberg, Adele E. and Ray Jackendoff (2004) "The English Resultative as a Family of Constructions," Language 80, 532-568.

Haspelmath, Martin (1997) Indefinite Pronouns, Oxford University Press, Oxford.

Haspelmath, Martin (2003) "The Geometry of Grammatical Meaning: Semantic Maps and Cross-linguistic Comparison," The New Psychology of Language, Vol. 2, ed. by Michael Tomasello, 211-242, Lawrence Erlbaum Associates, Mahwah, NJ.

Jackendoff, Ray (1983) Semantics and Cognition, MIT Press, Cambridge, MA.

Jackendoff, Ray (1997) “Twistin' the Night Away,” Language 73, 534-559.

Kroskrity, Paul V. (1985) "A Holistic Understanding of Arizona Tewa Passives," Language 61, 306-328.

Lakoff, George (1987) Women, Fire and Dangerous Things: What Categories Reveal about the Mind, University of Chicago Press, Chicago.

Lambrecht, Knud (1984) "Formulaicity, Frame Semantics and German Binomial Expressions," Language 60, 753-796.

Lambrecht, Knud (1988) "There Was a Farmer Had a Dog: Syntactic Amalgams Revisited," $B L S$ 14, 319-339.

Lambrecht, Knud (1990) ““What, Me Worry?”-'Mad Magazine' Sentences Revisited," BLS 16, 215-228.

Langacker, Ronald W. (1987) Foundations of Cognitive Grammar, Vol. I: Theoretical Prerequisites, Stanford University Press, Stanford.

Levin, Beth and Malka Rappaport Hovav (2005) Argument Realization, Cambridge University Press, Cambridge.

Levinson, Stephen C., Sérgio Meira and the Language and Cognition Group (2003) " Natural Concepts' in the Spatial Topological Domain-Adpositional Meanings in Crosslinguistic Perspective: An Exercise in Semantic Typology," Language 79, 485-516.

Levinson, Stephen C. and David Wilkins, eds. (2006) Grammars of Space: Explorations in Cognitive Diversity, Cambridge University Press, Cambridge.

Lieven, Elena, Heike Behrens, Jennifer Speares and Michael Tomasello (2003) "Early Syntactic Creativity: A Usage-Based Approach," Journal of Child Language 30, 333-370.

Majid, Asifa, James S. Boster and Melissa Bowerman (2008) "The Cross-linguistic Categorization of Everyday Events: A Study of Cutting and Breaking," Cognition 109, 239-250.

Michaelis, Laura A. and Knud Lambrecht (1996) "Toward a Construction-based 
Theory of Language Functions: The Case of Nominal Extraposition," Language $72,215-247$.

Pederson, Eric and Melissa Bowerman (In preparation) "ONwards from IN and INwards from ON: The Crosslinguistic Categorization of Topological Spatial Relationships," ms., University of Oregon.

Pierrehumbert, Janet B. (2003a) "Probabilistic Phonology: Discrimination and Robustness," Probabilistic Linguistics, ed. by Rens Bod, Jennifer Hay and Stefanie Jannedy, 177-228, MIT Press, Cambridge, MA.

Pierrehumbert, Janet B. (2003b) "Phonetic Diversity, Statistical Learning and Acquisition of Phonology," Language and Speech 46, 115-154.

Prince, Ellen F. (1978) "A Comparison of WH-clefts and It-clefts in Discourse," Language 54, 883-906.

Shibatani, Masayoshi (1985) "Passives and Related Constructions: A Prototype Analysis," Language 61, 821-848.

Siewierska, Anna (1985) The Passive: A Comparative Linguistic Analysis, Croom Helm, London.

Strömqvist, Sven and Ludo Verhoeven, eds. (2004) Relating Events in Narrative: Typological and Contextual Perspectives, Lawrence Erlbaum Associates, Mahwah, NJ.

Thompson, Chad (1994) "Passive and Inverse Constructions," Voice and Inversion, ed. by Talmy Givón, 47-63, John Benjamins, Amsterdam.

Tomasello, Michael (2003) Constructing a Language: A Usage-Based Theory of Language Acquisition, Harvard University Press, Cambridge, MA.

Wierzbicka, Anna (1980) Lingua Mentalis: The Semantics of Natural Language, Academic Press, New York.

Wierzbicka, Anna (1982) "Why Can You Have a Drink When You Can't *Have an Eat?" Language 58, 753-799.

Wierzbicka, Anna (1987) "Boys Will Be Boys," Language 63, 95-114.

[received September 9, 2013, revised and accepted November 24, 2013]

MSC03 Linguistics

1 University of New Mexico

Albuquerque NM 87131-0001

USA

e-mail: wcroft@unm.edu 